\title{
An Extended TODIM Based on Cumulative Prospect Theory and Its Application in Venture Capital
}

\author{
Xiaoli TIAN ${ }^{1}$, Zeshui $\mathrm{XU}^{1,2 *}$, Jing GU ${ }^{3}$ \\ ${ }^{1}$ Business School, State Key Laboratory of Hydraulics and Mountain River Engineering, \\ Sichuan University, Chengdu 610064, China \\ ${ }^{2}$ School of Computer and Software, Nanjing University of Information Science \& Technology, \\ Nanjing, Jiangsu 210044, China \\ ${ }^{3}$ School of Economics, Sichuan University, Chengdu 610064, China \\ e-mail: tianxiaolitxl@126.com,xuzeshui@263.net,gj0901@scu.edu.cn
}

Received: June 2018; accepted: January 2019

\begin{abstract}
An extended TODIM is proposed in this paper to comprehensively reflect the psychological characteristics of decision makers (DMs) according to cumulative prospect theory (CPT). We replace the original weight with the weighting function of CPT and modify the perceived value of the dominance based on CPT, because the general psychological phenomena of DMs explained in CPT are verified by many experiments and recognized by researchers. Hence, the extended TODIM not only integrates the advantages of CPT in considering the psychological factors of DMs but also retains the superiority of the classical TODIM in relative dominance. Finally, the extended TODIM is demonstrated to capture the psychological factors of DMs well from the case study.
\end{abstract}

Key words: multi-attributes decision-making, TODIM, cumulative prospect theory, venture capital.

\section{Introduction}

Due to the complex decision-making circumstance and the variable decision-making problems, the decision makers (DMs) rely on several different attributes to make their decisions. Therefore, individuals are faced with multi-attributes decision-making (MADM) problems every day, and also the MADM has been a hot topic in individuals' daily life (Liu et al., 2018; Zhang et al., 2019). Thus, the constructing of a proper MADM method for DMs to find an optimal alternative has recently attracted much attention from the researchers. Until now, a number of MADM methods related to how to select an optimal alternative has been established, and different aspects have been analysed by researchers to help DMs in pursuing a more reasonable and accurate way to solve MADM problem in reality, including TOPSIS (Technique for Order Preference by Similarity to an Ideal Solution) (Hwang and Yoon, 1981), VIKOR (Vlsekriterijumska optimizacija I KOmpromisno Resenje) (Opricovic, 1998), ELECTRE (ELimination Et Choix Traduisant

\footnotetext{
${ }^{*}$ Corresponding author.
} 
la REalité) (Roy, 1968), PROMETHEE (Preference Ranking Organization METhod for Enrichment Evaluations) (Brans, 1982; Brans and Vincke, 1985), TODIM (TOmada de Decisão Iterativa Multicritério) (Gomes and Lima, 1991), LINMAP (LINear programming technique for Multidimensional Analysis of Preferences) (Srinivasan and Shocker, 1973), QUALIFLEX (QUALItative FLEXible multiple criteria method) (Paelinck, 1978), COPRAS (COmplex PRoportional ASsessment COoperation) (Zavadskas et al., 1994), MULTIMOORA (MULTIple Multi-Objective Optimization by Ratio Analysis) (Brauers and Zavadskas, 2010), EDAS (Evaluation based on Distance from Average Solution) (Keshavarz Ghorabaee et al., 2015), BWM (Best-Worst Method) (Rezaei, 2015), ARAS (Additive Ratio Assessment) (Zavadskas and Turskis, 2010), and their variants, etc.

Among them, only TODIM considers the psychological states of DMs in decisionmaking process. It is based on the cumulative prospect theory (CPT) (Tversky and Kahneman, 1992) which is a great breakthrough in depicting the DMs' irrational behavioural decision-making under uncertainty. Actually, there are a lot of irrational behavioural factors during the decision-making process in reality. More specifically, the evaluating value given by DMs may be subjective because of the heterogeneity of risk preference of them. Even if all the DMs can reach agreement on risk attitude, the selecting results may still be different, since their evaluating values may be driven by the DMs' experience. Although many different evaluation methods on the selecting of the optimal alternative have been constructed, in the existing methods, seldom of them comprehensively concern the irrational situations. However, the classical TODIM is the one expressed by the partial irrational behaviour of DMs. Thus, in this study, according to the basic idea of TODIM, we are dedicated to modify this classical TODIM method in order to make the decisionmaking process more realistic.

There are some reasons to choose the TODIM as the basic tool for DMs to select an optimal alternative in this study. One reason is that the DMs' decision-making is a complex one which needs DMs to judge the alternatives from various aspects, and TODIM is one of the most popular tools in MADM. Secondly, investigating the superiority of an alternative not only takes into account the advantage of the alternative itself but also considers the relative superiority that it has compared with the other ones. The relative measurement of an alternative is precisely explored in TODIM and an overall dominance of an alternative to all the others is calculated through TODIM. Most importantly, those investigations are made by DMs whose decision-making may be more or less affected by their psychological states. Moreover, the TODIM is built on CPT which is an optional method to reflect the DMs' psychological behaviour. Thus, the TODIM is adopted in this study as the basic decision-making tool.

Although the classical TODIM is constructed on CPT, the core idea of CPT has not been captured in it. The CPT simulates the behaviour of DMs via the product of transformed weighting function and value function, which is demonstrated to be right from numerous experiments. The weighting function illustrates that the DMs make their decisions based on the nonlinear transformation of probabilities rather than the objective probabilities. That is tested by experiments (Birnbaum, 2005; Wu and Gonzalez, 1999; Gonzalez and $\mathrm{Wu}, 1999)$. The value function expresses that DMs perceive gains and 
losses differently. That is also demonstrated by experiments (Abdellaoui et al., 2007; Abdellaoui, 2000). However, in the classical TODIM, the weight of each attribute is expressed as objective probability and the perceived value is inconsistent with the value function of CPT. Therefore, in this paper, we intend to construct an extended TODIM method that integrates the merit of both classical TODIM and CPT to portray the psychological states of DMs for the sake of matching the fundamental nature of practical decision-making environment.

The main contributions of this study can be summarized as follows: (1) The transformed weighting function, which is a part of CPT and is demonstrated to be more in accordance with real decision-making of DMs, has been poured into the extended TODIM. (2) The value function in CPT, which is used to explain the general different risk attitudes for gains and losses, has been fully considered in the extended TODIM as well. (3) The perceived value of dominance has been adopted as the gist of decision-making in the extended TODIM, in other words, the two-part prospect function can explain the psychological value of DMs in reality more properly. (4) This extended TODIM is applied to the decision-making problem of venture capitalists (VCs). It has not only enriched the decision-making method for VCs but also made a good demonstration role for the uncertain decision-making in the other field.

The remainder of this study is organized as follows: Section 2 discusses the existing researches about TODIM, including both its extensions and its applications. In Section 3, a brief introduction of CPT and the classical TODIM has been presented, and then, the extended TODIM has been constructed to simulate the behavioural decision-making of DMs in reality. In Section 4, a decision-making problem in the Fortune Capital has been presented to demonstrate the effectiveness of the proposed method. Also, a comparative analysis between the proposed method and the classical TODIM has been shown in this section. Finally, Section 5 ends the study with some conclusions.

\section{Literature Review}

The traditional TODIM is proposed by Gomes and Lima (1991) for the first time, which is constructed on CPT to capture the psychological phenomena of DMs. It merely deals with a decision-making problem by crisp numbers. However, the complex decision-making circumstance makes it difficult to acquire the accurate evaluation information from DMs. Therefore, the classical TODIM has been extended to fuzzy circumstance as the development of a fuzzy set. For example, from the perspective of approval and opposition, TODIM has been established under intuitionistic fuzzy circumstance (Krohling et al., 2013; Lourenzutti and Krohling, 2013), interval-valued intuitionistic fuzzy circumstance (Krohling and Pacheco, 2014), triangular intuitionistic fuzzy circumstance (Qin et al., 2017). Moreover, the DMs may be indecisive to express their evaluation information because of the uncertain decision-making situation. Considering this, the TODIM has been combined with hesitant fuzzy information (Zhang and Xu, 2014; Tan et al., 2015; Ren et al., 2017; Zhang, 2017) and probabilistic hesitant fuzzy information (Zhang et al., 
2018) as well. Additionally, linguistic expression is common in our daily life (MorenteMolinera et al., 2019; Liao et al., 2018). In order to deal with the linguistic information, TODIM has been extended under intuitionistic linguistic circumstance (Yu et al., 2018; Wang and Liu, 2017; Liu and Teng, 2015), 2-dimension linguistic circumstance (Liu and Teng, 2016), Pythagorean linguistic circumstance (Geng et al., 2017), hesitant fuzzy linguistic circumstance (Wei et al., 2015; Yu et al., 2017; Wang et al., 2016). Although various fuzzy TODIM have been constructed, they are just a simple extension of the classical TODIM. Then, a generalized TODIM (Llamazares, 2018) is proposed to consider the risk attitudes' parameters according to PT.

Due to the superiority that TODIM can not only handle the MADM problem but also portray the psychological characteristic of DMs, it has been widely used in various fields of decision-making problems in reality, such as the evaluation and selection of rental residential properties (Gomes and Rangel, 2009), the problem of personnel selection (Ji et al., 2018) and the material selection (Zindani et al., 2017), hotel selection (Yu et al., 2018), the efficiency evaluation of sustainable water management (Zhang and Xu, 2016), the selection of ERP software (Kazancoglu and Burmaoglu, 2013) and green supplier (Sang and Liu, 2016), medical treatment selection (Hu et al., 2017), etc.

Although the classical TODIM has been extended in various fuzzy circumstances and accepted by DMs to settle a number of MADM problems, none of them notice that this classical TODIM, which is based on CPT, could not properly simulate the behavioural decision-making of DMs explained in CPT. For instance, according to CPT, the DMs rely on the transformed probability weighting function (the perceived probability: overweight or underweight probability) rather than the unidimensional probability weighting value (the objective probability) to make their decisions (Abdellaoui et al., 2007; Birnbaum, 2005; Gonzalez and Wu, 1999; Wu and Gonzalez, 1999). However, none of the existing TODIM adopts the weighting function to obtain the relative weight in the dominance function. So, it is necessary to include such a situation into the classical TODIM. In addition, although the gains or losses instead of final states of wealth are incorporated in the classical TODIM, they are inconsistent with the perceived gains or losses in value function of the prominent CPT. Although Tan et al. (2015) and Llamazares (2018) used the parameters of risk attitudes of value function in CPT to take the place of the square root of the dominance function in TODIM, both of them thought that parameters of risk attitudes work on the product of relative weight and the gains or losses as a whole part. However, in the classical CPT, the parameters of risk attitudes only affect the gains or losses of the value function, but not the whole part of weighting function and evaluation function. To summarize, in this study, an extended TODIM based on CPT is constructed. It considers the transformed probability weighting function to obtain the relative weight. Also, in this extended TODIM, the parameters of risk attitudes only affect the value function. Then, dominance function is the product of the relative weight and the value function. This extended TODIM completely accords with the CPT. It can help DMs to make a more reasonable decision-making as well. 


\section{An Extended TODIM for Decision-Making}

In this section, we first present CPT and the classical TODIM method as the antecedent methods of our extended selection method for DMs. Then, the extended TODIM method is proposed to illustrate how we integrate CPT and the classical TODIM method to optimize the selection process for DMs.

\subsection{Cumulative Prospect Theory}

It is a well-known theory proposed by Tversky and Kahneman (1992) and applied in decision-making with uncertain environment. The crucial part of this theory can be constructed as a prospect function $V\left(x_{j}\right)$, which can be described as the product of two functions: the value function $v\left(x_{j}\right)$ and the transformed probability weighting function $\pi\left(p_{j}\right)$.

$$
V\left(x_{j}\right)=\sum_{j=1}^{m} v\left(x_{j}\right) \pi\left(p_{j}\right),
$$

where $m$ is the number of attributes for alternatives; $j$ expresses the $j$ th attribute; $v\left(x_{j}\right)$ reflects the perceived gains or losses, which are defined as follows:

$$
v\left(x_{j}\right)= \begin{cases}\left(x_{j}-x_{0}\right)^{\alpha}, & \text { if } x_{j}-x_{0} \geqslant 0, \\ -\lambda\left(x_{0}-x_{j}\right)^{\beta}, & \text { if } x_{j}-x_{0}<0\end{cases}
$$

where $x_{j}$ shows the value of the $j$ th attribute, while $x_{0}$ expresses the reference point perceived by DMs; thereby, $x_{j}-x_{0}>0$ represents the gain; on the contrary, $x_{j}-x_{0}<0$ shows the loss; In addition, $x_{j}-x_{0}=0$ explains that there is no gain or loss relative to the reference point; $\alpha$ and $\beta$ are the parameters of DMs' risk attitudes and they are viewed as preference degrees in the domain of gain and loss, respectively; $\lambda$ is the parameter of loss aversion that is more sensitive to loss than gain. The value function reflects the different risk attitudes for gains and losses.

When $x_{j}-x_{0} \geqslant 0$, the weighting function is determined by:

$$
\pi^{+}\left(p_{j}\right)=p_{j}^{\gamma} /\left(p_{j}^{\gamma}+\left(1-p_{j}\right)^{\gamma}\right)^{\frac{1}{\gamma}} .
$$

Otherwise,

$$
\pi^{-}\left(p_{j}\right)=p_{j}^{\delta} /\left(p_{j}^{\delta}+\left(1-p_{j}\right)^{\delta}\right)^{\frac{1}{\delta}},
$$

where $p_{j}$ is probability of $x_{j}$; both $\gamma$ and $\delta$ are the parameters describing the curvature of the weighting function and they express the differences of diminishing sensitivity in the domain of gains and losses.

The value function illustrates that the DMs are risk averse when gains occur; however, they are risk seeking when losses occur. Besides, since the weighting function can represent the extent of risk attitude of DMs, it is obvious that the effect of risk aversion is 
greater than that of risk seeking in most environments, which is consistent with previous studies.

\subsection{Classical TODIM Method}

The classical TODIM is applied to MADM through the measurement of relative dominance degree for each alternative over the others. The ranking result is presented from the comparison of the relative dominance degree of each alternative over the others and based on which the DMs will find the optimal one.

A MADM problem can be abstracted as a decision matrix $X$ obtained from DMs, which includes all the available alternatives $A=\left\{A_{1}, A_{2}, \ldots, A_{n}\right\}$ and all the attributes $C=\left\{C_{1}, C_{2}, \ldots, C_{m}\right\}$. It is described as follows:

$$
X=\left(\begin{array}{ccc}
x_{11} & \cdots & x_{1 m} \\
\vdots & \ddots & \vdots \\
x_{n 1} & \cdots & x_{n m}
\end{array}\right)=\left(x_{i j}\right)_{n \times m}, \quad \omega=\left(\omega_{1}, \omega_{2}, \ldots, \omega_{m}\right), \quad \sum_{j=1}^{m} \omega_{j}=1
$$

where $x_{i j}$ is the value of the $j$ th attribute for the alternative $i$ from DMs; $\omega_{j}$ is the original weight of the $j$ th attribute.

For convenience, let $N=\{1,2, \ldots, n\}$ and $M=\{1,2, \ldots, m\}$. The classical TODIM method involves the following steps:

Step 1. Standardize the decision matrix $X=\left(x_{i j}\right)_{n \times m}$ into $G=\left(g_{i j}\right)_{n \times m}, i \in N, j \in M$.

$$
g_{i j}= \begin{cases}x_{i j}, & j \text { is benefit atrribute, } \\ -x_{i j}, & j \text { is cost atrribute. }\end{cases}
$$

Step 2. Calculate the relative weight $\omega_{j r}$ from (6):

$$
\omega_{j r}=\omega_{j} / \omega_{r}, \quad r, j \in M,
$$

where $\omega_{j}$ and $\omega_{r}$ are the original weights of the attributes $C_{j}$ and $C_{r}$ correspondingly and $\omega_{r}=\max \left(\omega_{j} \mid j \in N\right) ; C_{r}$ is called a reference attribute.

Step 3. Determine the dominance of the alternative $A_{i}$ over each alternative $A_{k}(i, k \in N)$ depending on (7):

$$
\psi\left(A_{i}, A_{k}\right)=\sum_{j=1}^{m} \varphi_{j}\left(A_{i}, A_{k}\right), \quad \forall(i, k),
$$

where

$$
\varphi_{j}\left(A_{i}, A_{k}\right)= \begin{cases}\sqrt{\omega_{j k}\left(g_{i j}-g_{k j}\right) / \sum_{j=1}^{m} \omega_{j k}}, & \text { if } g_{i j}>g_{k j}, \\ 0, & \text { if } g_{i j}=g_{k j}, \\ \frac{-1}{\theta} \sqrt{\left(\sum_{j=1}^{m} \omega_{j k}\right)\left(g_{k j}-g_{i j}\right) / \omega_{j k}}, & \text { if } g_{i j}<g_{k j} .\end{cases}
$$


The $\varphi_{j}\left(A_{i}, A_{k}\right)$ explains the contribution of the attribute $C_{j}$ to the function $\psi\left(A_{i}, A_{k}\right)$ when comparing the dominance of the alternative $A_{i}$ to the alternative $A_{k}$. The parameter $\theta$ shows the attenuation factor of the losses, which can be turned on account of the problem faced with. Three cases will be presented in (8): (1) if $g_{i j}>g_{k j}$, then it states a gain; (2) if $g_{i j}<g_{k j}$, then it describes a loss; (3) if $g_{i j}=g_{k j}$, then it represents a nil, that is, neither gain nor loss.

Step 4. Obtain the overall value of the alternative $A_{i}$ on the basis of (9):

$$
\Psi\left(A_{i}\right)=\frac{\sum_{k=1}^{n} \psi\left(A_{i}, A_{k}\right)-\min _{i}\left\{\sum_{k=1}^{n} \psi\left(A_{i}, A_{k}\right)\right\}}{\max _{i}\left\{\sum_{k=1}^{n} \psi\left(A_{i}, A_{k}\right)\right\}-\min _{i}\left\{\sum_{k=1}^{n} \psi\left(A_{i}, A_{k}\right)\right\}}, \quad i \in N
$$

Step 5. Rank the overall value $\Psi\left(A_{i}\right), i \in N$, based on which the promising alternative is then found. The bigger of the overall value $\Psi\left(A_{i}\right)$ is, the better the alternative $A_{i}$ will be.

\subsection{An Extended TODIM Method}

Although the classical TODIM considers relative importance of attributes, this method neither provides an appropriate way to determine the weights of attributes nor comprehensively expresses the real perceptions for gains or losses of DMs. Generally, there are two significant hurdles when the classical TODIM is applied in decision-making environment. First, the weight determination of an attribute is presented as an objective probability in the classical TODIM, which is accused of a deviation from decision-making practice by Mattos and Garcia (2011). According to their opinions, the weight of an attribute should be a transformed probability weighting function, driving from CPT to improve the efficiency of decision-making for DMs. Second, although the gains or losses instead of final states of wealth are incorporated in the classical TODIM, they are inconsistent with the perceived gains or losses in value function of the prominent CPT. The real perceptions of gains or losses are well captured by the value function of CPT. Applying the transformed weighting function and value function of the prominent CPT into the extended TODIM can not only make the method more suitable for decision-making environment but also increase the accuracy of decisions for DMs.

In this study, a deep modification of the classical TODIM is proposed, which incorporates prospect function (the product of the transformed weighting function and the value function described in Section 3.1 to respectively identify the weights of attributes and describe the different risk attitudes for gains and losses of DMs) as the relative dominance. Compared with the classical TODIM, this extended TODIM is more appropriate for DMs' decision-making in both accurate and efficient perspectives. The construction of the extended TODIM is described step by step as follows: We suppose that there are $n$ alternatives i.e. $A=\left\{A_{1}, A_{2}, \ldots, A_{n}\right\}$. For each alternative, there are $m$ attributes, i.e. $C=\left\{C_{1}, C_{2}, \ldots, C_{m}\right\}$. 
Step 1. Identify the decision matrix and attribute values from DMs described as follows:

$$
X=\left(\begin{array}{ccc}
x_{11} & \cdots & x_{1 m} \\
\vdots & \ddots & \vdots \\
x_{n 1} & \cdots & x_{n m}
\end{array}\right)=\left(x_{i j}\right)_{n \times m}, \quad w=\left(w_{1}, w_{2}, \ldots, w_{m}\right), \quad \sum_{j=1}^{m} w_{j}=1
$$

Step 2. Work out the transformed probability of the alternative $A_{i}$ to $A_{k}, k \in M$ and $k \neq i$ according to (10) or (11).

When $x_{i j}-x_{k j} \geqslant 0$, the transformed probability weight is acquired by (10):

$$
\pi_{i k j}^{+}\left(w_{j}\right)=w_{j}^{\gamma} /\left(w_{j}^{\gamma}+\left(1-w_{j}\right)^{\gamma}\right)^{\frac{1}{\gamma}}
$$

Otherwise, the transformed probability weight is calculated from (11):

$$
\pi_{i k j}^{-}\left(w_{j}\right)=w_{j}^{\delta} /\left(w_{j}^{\delta}+\left(1-w_{j}\right)^{\delta}\right)^{\frac{1}{\delta}}
$$

where $\gamma$ and $\delta$ are the parameters defined in Section 3.1.

Step 3. Determine the relative weight $\pi_{i k j *}$ for the alternative $A_{i}$ to the alternative $A_{k}$ from (12):

$$
\pi_{i k j^{*}}=\pi_{i k j}\left(w_{j}\right) / \pi_{i k r}\left(w_{r}\right), \quad r, j \in M, \forall(i, k)
$$

where $\pi_{i k j}\left(w_{j}\right)$ and $\pi_{i k r}\left(w_{r}\right)$ are all acquired from (10) or (11) for the alternative $A_{i}$ to $A_{k}$ depending on the value of $x_{i j}-x_{k j}$; while $\pi_{i k j}\left(w_{j}\right)$ represents the transformed weight of the $j$ th attribute for the alternative $A_{i} ; \pi_{i k r}\left(w_{r}\right)$ refers to the transformed weight of reference attribute for the alternative $A_{i}$ to $A_{k}$ satisfying $\pi_{i k r}\left(w_{r}\right)=\max \left(\pi_{i k j}\left(w_{j}\right) \mid\right.$ $j \in M)$.

Step 4. Calculate the relative prospect dominance of the alternative $A_{i}$ over $A_{k}$ under the attribute $j$ with (13):

$$
\varphi_{j^{*}}\left(A_{i}, A_{k}\right)= \begin{cases}\pi_{i k j^{*}}\left(x_{i j}-x_{k j}\right)^{\alpha} / \sum_{j^{*}=1}^{m} \pi_{i k j^{*}}, & \text { if } x_{i j}>x_{k j}, \\ 0, & \text { if } x_{i j}=x_{k j}, \\ -\lambda\left(\sum_{j^{*}=1}^{m} \pi_{i k j^{*}}\right)\left(x_{k j}-x_{i j}\right)^{\beta} / \pi_{i k j^{*}}, & \text { if } x_{i j}<x_{k j},\end{cases}
$$

where $\alpha, \beta$, and $\lambda$ are the parameters defined in Section 3.1.

Step 5. Aggregate the relative prospect dominance of the alternative $A_{i}$ over $A_{k}$ under all the attributes depending on (14):

$$
\psi\left(A_{i}, A_{k}\right)=\sum_{j^{*}=1}^{m} \varphi_{j}^{*}\left(A_{i}, A_{k}\right), \quad \forall(i, k) .
$$


Step 6. Obtain the overall prospect dominance of the alternative $A_{i}$ based on (9).

Step 7. Rank the overall prospect dominance $\Psi\left(A_{i}\right), i \in N$, based on which the optimal alternative is then found. The bigger the overall prospect value $\Psi\left(A_{i}\right)$ is, the better the project $A_{i}$ will be.

According to the steps above, this extended TODIM includes the transformed probability weighting function and the proper value function in CPT, which is more consistent with reality theoretically. Then, an example is shown in the next section to demonstrate the practical effectiveness of the proposed method.

\section{Case Study}

In this section, an example in the Fortune Capital $^{2}$ has been provided to discuss the advantages of the extended TODIM. The Fortune Capital has been rated as one of the China's top 50 best venture capital (VC) institutions since 2001 to 2017. It also obtained the honour as the optimal VC firm and VC exit winner of China at the annual meeting of the investment community in the year 2015 and 2012, respectively. It was established in April 2000 as the first domestic batch that operated according to the market-oriented institution. At present, the Fortune Capital is already operating 19 funds, and the total capital of the funds has reached over 25 billion CNY. Over 450 enterprises have acquired capital from the Fortune Capital. Furthermore, 115 have already exited successfully through IPO (73) or M\&A (merger and acquisition) (42). As the famous VC institution, the Fortune Capital receives thousands of projects every day. How to select a promising one from numerous projects has been a constant question for VCs in the Fortune Capital.

The proposed TODIM modifies the unidimensional weight as a form of weighting function and takes the real perceptions for gains or losses into consideration. Although it is reasonable theoretically, the practical importance will also be demonstrated in this section with a real example of selecting the promising project in the Fortune Capital.

\subsection{The Screening Process with the Extended TODIM Method}

As the overexploitation of natural resources by humans and the enhanced awareness of sustainable development grows, new energy has attracted a lot of attention of both governments and customers. For instance, the governments subsidize the manufacturers of new automobile energy with reduction of rates and encourage customers to buy them with price support. Thus, the industry of new energy has great prospect and has already attracted many investors, including the Fortune Capital. After preliminary investigation, four VC projects (thermal power $A_{1}$, wind power generation $A_{2}$, hydroelectric power $A_{3}$, solar photovoltaics $A_{4}$ ) remain to be further investigated. First, we draw on previous research (Nunes et al., 2014; Dhochak and Sharma, 2015; Widyanto and Dalimunthe, 2015) to find out an appropriate evaluation attributes' system used by VCs in the selection process as Table 1 shows.

\footnotetext{
${ }^{2}$ http://www.fortunevc.com/en/.
} 
Table 1

The attributes used by VCs in decision-making.

\begin{tabular}{ll}
\hline Aspects & Attributes \\
\hline Management team & The familiar degree of target market $\left(C_{1}\right)$ \\
& The effort level $\left(C_{2}\right)$ \\
& The ability of evaluating and reacting to the risk $\left(C_{3}\right)$ \\
& The ability of leadership $\left(C_{4}\right)$ \\
& The related experience and acquired relevant performance $\left(C_{5}\right)$ \\
& The explicit plan $\left(C_{6}\right)$ \\
Service or product & Realized the initial functioning prototype $\left(C_{7}\right)$ \\
& Accepted by market $\left(C_{8}\right)$ \\
& The degree of being protected $\left(C_{9}\right)$ \\
Finance & At least 10 times revenue acquired with 10 years $\left(C_{10}\right)$ \\
Market & Easily cashability $\left(C_{11}\right)$ \\
& Significant growth $\left(C_{12}\right)$ \\
\hline
\end{tabular}

Table 2

The evaluation matrix.

\begin{tabular}{lllllllllllll}
\hline & $C_{1}$ & $C_{2}$ & $C_{3}$ & $C_{4}$ & $C_{5}$ & $C_{6}$ & $C_{7}$ & $C_{8}$ & $C_{9}$ & $C_{10}$ & $C_{11}$ & $C_{12}$ \\
\hline$A_{1}$ & 88 & 92 & 80 & 71 & 88 & 72 & 83 & 68 & 96 & 70 & 77 & 79 \\
$A_{2}$ & 79 & 80 & 89 & 90 & 69 & 83 & 79 & 73 & 86 & 77 & 84 & 90 \\
$A_{3}$ & 81 & 69 & 91 & 76 & 82 & 74 & 85 & 78 & 88 & 81 & 88 & 91 \\
$A_{4}$ & 93 & 78 & 90 & 75 & 80 & 65 & 82 & 80 & 89 & 83 & 80 & 94 \\
\hline
\end{tabular}

According to Widyanto and Dalimunthe (2015), the weights of attributes are calculated as: $\omega_{C}=\left(\omega_{C_{1}}, \omega_{C_{2}}, \ldots, \omega_{C_{12}}\right)=(0.098,0.098,0.092,0.087,0.085,0.0760 .080 .077$, $0.0740 .0750 .0740 .086){ }^{3}$ Then, the promising project is obtained by using the extended TODIM step by step.

Step 1. We have invited some senior investors to investigate the prospect of the remaining four projects under each attribute. After deliberate thinking and discussion, they have given the consistent evaluating information. It can be seen in Table $2 .^{4}$

At this point, Step 1 has already been finished. Next, we take the alternative $A_{1}$ for an example to calculate its overall prospect dominance.

Step 2. The transformed probability weight $\pi_{1 k j}$ is calculated according to (10) or (11), which depends on the relative value of the alternative $A_{1}$ to the others under all attributes and it can be seen in Table 3.

\footnotetext{
${ }^{3}$ This reference introduced investigated data about attributes used by VCs in numerous countries and we comprehensively aggregated those data as the weights of attributes in this paper. We believe that those comprehensive weights are reasonable.

${ }^{4}$ The VCs give each attribute of each alternative a value. Furthermore, the value ranges from 0 to 100 . For the benefit attribute, the higher the value is, the better the alternative will be. It is contrary for the cost attribute.
} 
Table 3

The transformed probability weight for each attribute.

\begin{tabular}{lllllllllllll}
\hline & $C_{1}$ & $C_{2}$ & $C_{3}$ & $C_{4}$ & $C_{5}$ & $C_{6}$ & $C_{7}$ & $C_{8}$ & $C_{9}$ & $C_{10}$ & $C_{11}$ & $C_{12}$ \\
\hline$\pi_{12}$ & 0.18 & 0.18 & 0.14 & 0.17 & 0.17 & 0.15 & 0.17 & 0.14 & 0.16 & 0.14 & 0.15 & 0.15 \\
$\pi_{13}$ & 0.18 & 0.18 & 0.14 & 0.17 & 0.17 & 0.15 & 0.17 & 0.14 & 0.16 & 0.14 & 0.15 & 0.15 \\
$\pi_{14}$ & 0.17 & 0.18 & 0.14 & 0.17 & 0.17 & 0.17 & 0.17 & 0.14 & 0.16 & 0.14 & 0.15 & 0.15 \\
\hline
\end{tabular}

Note: Here, $\gamma=0.61, \delta=0.69$ in (10) and (11) correspondingly. The values of them come from the experiment conducted by Tversky and Kahneman (1992) and they are accepted by most researchers.

Table 4

The relative weight for each attribute.

\begin{tabular}{lllllllllllll}
\hline & $C_{1 *}$ & $C_{2 *}$ & $C_{3^{*}}$ & $C_{4 *}$ & $C_{5^{*}}$ & $C_{6^{*}}$ & $C_{7^{*}}$ & $C_{8^{*}}$ & $C_{9^{*}}$ & $C_{10^{*}}$ & $C_{11^{*}}$ & $C_{12^{*}}$ \\
\hline$\pi_{12}$ & 1.0 & 0.97 & 0.79 & 0.91 & 0.94 & 0.84 & 0.94 & 0.78 & 0.87 & 0.77 & 0.79 & 0.81 \\
$\pi_{13}$ & 1.0 & 0.97 & 0.79 & 0.91 & 0.94 & 0.84 & 0.94 & 0.78 & 0.87 & 0.77 & 0.79 & 0.81 \\
$\pi_{14}$ & 0.94 & 1.00 & 0.81 & 0.94 & 0.97 & 0.96 & 0.97 & 0.80 & 0.90 & 0.79 & 0.81 & 0.83 \\
\hline
\end{tabular}

Table 5

The relative prospect dominance for each attribute.

\begin{tabular}{lllllllllllll}
\hline & $C_{1 *}$ & $C_{2 *}$ & $C_{3}$ & $C_{4 *}$ & $C_{5 *}$ & $C_{6 *}$ & $C_{7 *}$ & $C_{8 *}$ & $C_{9 *}$ & $C_{10 *}$ & $C_{11 *}$ & $C_{12 *}$ \\
\hline$\varphi_{j *}\left(A_{1}, A_{2}\right)$ & 0.66 & 0.71 & -165.09 & -310.52 & 1.21 & -230.78 & 0.31 & -145.25 & 0.64 & -251.48 & -164.55 & -239.00 \\
$\varphi_{j *}\left(A_{1}, A_{3}\right)$ & 0.53 & 1.47 & -245.73 & -67.48 & 0.44 & -51.49 & 0.24 & -227.68 & 0.91 & -210.77 & -244.93 & -239.00 \\
$\varphi_{j *}\left(A_{1}, A_{4}\right)$ & -67.62 & 0.95 & -226.11 & -47.26 & 0.57 & 0.50 & 0.09 & -267.49 & 1.01 & -271.68 & -100.63 & -314.21 \\
\hline
\end{tabular}

Note: The $\alpha=0.88, \beta=0.88, \lambda=2.25$ in Eq. (13). The values of them come from the experiment conducted by Tversky and Kahneman (1992) and they are accepted by most researchers.

Table 6

The relative prospect dominance.

\begin{tabular}{ccc}
\hline$\psi\left(A_{1}, A_{2}\right)$ & $\psi\left(A_{1}, A_{3}\right)$ & $\psi\left(A_{1}, A_{4}\right)$ \\
\hline-1503.13 & -1283.48 & -1291.88 \\
\hline
\end{tabular}

Step 3. From the transformed probability weight obtained in Step 2, the relative weight $\pi_{1 k j *}$ of the alternative $A_{1}$ to the others under each attribute is worked out according to (12). It is shown in Table 4.

Step 4. The relative prospect dominance of the alternative $A_{1}$ over the others for each attribute will be determined according to (13) and the result is presented in Table 5.

Step 5. The relative prospect dominance of the alternative $A_{1}$ over the others based on (14) is acquired and shown in Table 6.

Step 6. The overall prospect dominance of each alternative will be calculated by repeating Steps 2 to 5 and (9). The results are shown in Table 7.

Step 7. It is known that $\Psi\left(A_{4}\right)>\Psi\left(A_{2}\right)>\Psi\left(A_{3}\right)>\Psi\left(A_{1}\right)$, so $A_{4} \succ A_{2} \succ A_{3} \succ A_{1}$. 
Table 7

The overall prospect dominance.

\begin{tabular}{llll}
\hline$\Psi\left(A_{1}\right)$ & $\Psi\left(A_{2}\right)$ & $\Psi\left(A_{3}\right)$ & $\Psi\left(A_{4}\right)$ \\
\hline 0 & 0.94 & 0.89 & 1 \\
\hline
\end{tabular}

Table 8

The relative weight.

\begin{tabular}{lllllllllllll}
\hline & $C_{1}$ & $C_{2}$ & $C_{3}$ & $C_{4}$ & $C_{5}$ & $C_{6}$ & $C_{7}$ & $C_{8}$ & $C_{9}$ & $C_{10}$ & $C_{11}$ & $C_{12}$ \\
\hline$\omega_{j r}$ & 0.998 & 0.939 & 0.782 & 1 & 0.889 & 0.867 & 0.875 & 0.772 & 0.755 & 0.752 & 0.786 & 0.818 \\
\hline
\end{tabular}

Table 9

The dominance of each alternative over the others.

\begin{tabular}{lllll}
\hline$\psi\left(A_{i}, A_{k}\right)$ & $A_{1}$ & $A_{2}$ & $A_{3}$ & $A_{4}$ \\
\hline$A_{1}$ & 0 & -29.41 & -25.96 & -25.99 \\
$A_{2}$ & -17.47 & 0 & -14.50 & -19.85 \\
$A_{3}$ & -18.06 & -17.71 & 0 & -16.33 \\
$A_{4}$ & -16.66 & -17.47 & -12.57 & 0 \\
\hline
\end{tabular}

The alternative $A_{4}$ is recognized as the best option among the four alternatives, whereas $A_{1}$ is regarded as the worst one.

The results above rely on the degrees of risk attitudes of VCs, that is to say, the results depend on the values of the parameters $\alpha, \beta, \lambda, \gamma$ and $\delta$, but the great difference between the proposed method and the classical TODIM lies in the prospect function which is the product of disparate weighting function and the value function.

\subsection{The Screening Process with the Classical TODIM Method}

In this section, the classical TODIM (Gomes and Lima, 1991) is processed for the sake of comparing it with the extended one. In order to compare those two methods more conveniently, the decision-making information in Table 1 and Table 2 is adopted here as well. Then, the overall dominance of each alternative is calculated depending on the steps in Section 3.2.

Step 1. According to the attribute in Table 1 and the decision-making matrix in Table 2, it is known that there is $X=\left(x_{i j}\right)_{n \times m}=G=\left(g_{i j}\right)_{n \times m}$ due to the fact that all the attributes are the benefit ones. The attribute weights are also calculated via Widyanto and Dalimunthe (2015) as shown in Section 4.1.

Step 2. The relative weight of each attribute is obtained from (6) and it is shown in Table 8.

Step 3. The dominance of each alternative $A_{i}$ over each alternative $A_{k}(i, k \in N)$ shown in Table 9 depends on (7) and (8).

Step 4. The overall value of each alternative is shown in Table 10 based on (9). 
Table 10

The overall dominance of each alternative.

\begin{tabular}{lllll}
\hline & $A_{1}$ & $A_{2}$ & $A_{3}$ & $A_{4}$ \\
\hline$\Psi\left(A_{i}\right)$ & 0 & 0.85 & 0.84 & 1 \\
\hline
\end{tabular}

Table 11

The results of the two methods.

\begin{tabular}{lllll}
\hline The overall dominance & $\Psi\left(A_{1}\right)$ & $\Psi\left(A_{2}\right)$ & $\Psi\left(A_{3}\right)$ & $\Psi\left(A_{4}\right)$ \\
\hline The extended TODIM & 0 & 0.94 & 0.89 & 1 \\
The classical TODIM & 0 & 0.85 & 0.84 & 1 \\
\hline
\end{tabular}

Step 5. From Table 10, it is known that $\Psi\left(A_{4}\right)>\Psi\left(A_{2}\right)>\Psi\left(A_{3}\right)>\Psi\left(A_{1}\right)$, that is to say, $A_{4} \succ A_{2} \succ A_{3} \succ A_{1}$.

The ranking result explains that the alternative $A_{4}$ is the best choice and $A_{2}$ is the suboptimal one, however, $A_{1}$ is the worst option.

\subsection{The Comparison of These Two Methods}

From the results of Section 4.1 and Section 4.2, it is known that the ranking results from the two methods are the same. The alternatives $A_{4}$ and $A_{1}$ are recognized as the promising project and the unworthy one respectively in both the extended TODIM and the classical TODIM. The overall dominance derived from the two methods is shown in Table 11, and then, a comparative analysis between the extended TODIM and the classical TODIM is provided in this section.

Although the ranking results of the four projects from the two methods are consistent, the great difference between the proposed method and the classical TODIM lies in the disparate weighting function and value function. From Table 11, it is easy to see that the overall dominance of them is different between the two methods as well. The main reason for such a difference ranking is: the evaluating information of the extended TODIM is presented as prospect values which are the product of value functions (nonlinear gains or losses) and the transformed weights of attributes for VC projects, whereas, the evaluating information of the classical TODIM comes from the product of linear gains or losses and the objective probability that could not reflect the psychological perception of VCs for projects. In theoretical terms, the extended TODIM accompanied with value function and transformed weighting function confirms that the real decision-making situation is more reasonable as the aid for investors. In practical terms, the investors admit such a weighting function in our interview as well. Also, the extended TODIM increases the difference between the alternatives. For instance, the difference of overall dominance between $A_{2}$ and $A_{3}$ with extended TODIM is larger than with the classical one. This is very useful, especially for the choice among the similar alternatives. To sum up, the extended TODIM is feasible and suitable for investors to make their decisions. 


\section{Conclusions}

The traditional decision-making methods have focused on the decision-making with assumption of perfect rationality. However, these previous methods seldom considered the irrational characteristics of DMs, which are always significant to the evaluation information and the DMs' decision-making. Although the TODIM is a useful tool to simulate the irrational parts of DMs, it could not reflect overall DMs' psychological states explained in CPT. Hence, in this study, we have extended the classical TODIM method on the basis of prospect value in CPT for the sake of comprehensively handling the irrational decisionmaking of DMs. Besides, by a case study, the extended decision-making method (extended TODIM) constructed in this paper has been proven to be superior to the classical one.

Although the extended TODIM is well applied in VC, we only consider the VC problem in this paper and ignore the application of DMs' psychology in other fields. Furthermore, we believe that this study may provide inspiration for follow-up research of decisionmaking methods under the framework of bounded rationality. Meanwhile, we will focus on extending the decision-making method under fuzzy decision-making circumstance with bounded rationality of DMs in the future.

Acknowledgements. This research was funded by the National Natural Science Foundation of China (Nos. 71771155, 71571123), also funded by the Fundamental Research Funds of the Central Universities for Joint Innovation Project between Teachers and Students of Business School in Sichuan University (Nos. LH2018015) and by the Doctoral Graduate Student's Academic Visit Fund of Sichuan University.

\section{References}

Abdellaoui, M. (2000). Parameter-free elicitation of utility and probability weighting functions. Management Science, 46(11), 1497-1512.

Abdellaoui, M., Bleichrodt, H., Paraschiv, C. (2007). Loss aversion under prospect theory: a parameter-free measurement. Management Science, 53(10), 1659-1674.

Birnbaum, M.H. (2005). Three new tests of independence that differentiate models of risky decision making. Management Science, 51(9), 1346-1358.

Brans, J.P. (1982). L'ingéničrie de la décision; Elaboration d'instruments d'aide ą la décision. La méthode PROMETHEE. In: Nadeau, R., Landry, M. (Eds.), L'aide ą la décision: Nature, Instruments et Perspectives d'Avenir. Que 'bec, Presses de l'Universite' Laval, Canada, pp. 183-214.

Brans, J.P., Vincke, P.H. (1985). A preference ranking organization method. Management Science, 31(6), 647656.

Brauers, W.K.M., Zavadskas, E.K. (2010). Project management by MULTIMOORA as an instrument for transition economies. Technological and Economic Development of Economy, 16(1), 5-24.

Dhochak M., Sharma, A.K. (2015). Venture capitalists' investment decision criteria for new ventures: a review. Procedia-Social and Behavioral Sciences, 189, 465-470.

Geng, Y.S., Liu, P.D., Teng, F., Liu, Z.M. (2017). Pythagorean fuzzy uncertain linguistic TODIM method and their application to multiple criteria group decision making. Journal of Intelligent and Fuzzy Systems, 33(6), 3383-3395.

Gomes, L.F.A.M., Lima, M.M.P.P. (1991). TODIM: basic and application to multicriteria ranking of projects with environmental impacts. Foundations of Computing and Decision Sciences, 16(4), 113-127.

Gomes, L.F.A.M., Rangel, L.A.D. (2009). An application of the TODIM method to the multicriteria rental evaluation of residential properties. European Journal of Operational Research, 193(1), 204-211. 
Gonzalez, R., Wu, G. (1999). On the shape of the probability weighting function. Cognitive Psychology, 38(1), $129-166$.

Hu, J.H., Yang, Y., Chen, X.H. (2017). A novel TODIM method-based three-way decision model for medical treatment selection. International Journal of Fuzzy Systems, (6), 1-16.

Hwang, C.L., Yoon, K.P. (1981). Multiple Attribute Decision Making: Methods and Applications. SpringerVerlag, New York.

Ji, P., Zhang, H.Y., Wang, J.Q. (2018). A projection-based TODIM method under multi-valued neutrosophic environments and its application in personnel selection. Neural Computing and Applications, 29(1), 221234.

Keshavarz Ghorabaee, M., Zavadskas, E.K., Olfat, L., Turskis, Z. (2015). Multi-criteria inventory classification using a new method of evaluation based on distance from average solution (EDAS). Informatica, 26(3), 435-451.

Krohling, R.A., Pacheco, A.G.G. (2014). Interval-valued intuitionistic fuzzy TODIM. Procedia Computer Science, 31, 236-244.

Krohling, R.A., Pacheco, A.G.G., Siviero, A.L.T. (2013). IF-TODIM: an intuitionistic fuzzy TODIM to multicriteria decision making. Knowledge-Based Systems, 53(9), 142-146.

Llamazares, B. (2018). An analysis of the generalized TODIM method. European Journal of Operational Research, 269(3), 1041-1049.

Liao, H.C., Xu, Z.S., Herrera-Viedma, E., Herrera, F. (2018). Hesitant fuzzy linguistic term set and its application in decision making: a state-of-the-art survey. International Journal of Fuzzy Systems, 20(7), 2084-2110.

Liu, P.D., Teng, F. (2015). An extended TODIM method for multiple attribute group decision making based on intuitionistic uncertain linguistic variables. Journal of Intelligent and Fuzzy Systems, 29(2), 701-711.

Liu, P.D., Teng, F. (2016). An extended TODIM method for multiple attribute group decision-making based on 2-dimension uncertain linguistic variable. Complexity, 21(5), 20-30.

Liu, Y.T., Dong, Y.C., Liang, H.M., Chiclana, F., Herrera-Viedma, E. (2018). Multiple attribute strategic weight manipulation with minimum cost in a group decision making context with interval attribute weights information. IEEE Transactions on Systems, Man, and Cybernetics: Systems. doi:10.1109/TSMC.2018.2874942.

Lourenzutti, R., Krohling, R.A. (2013). A study of TODIM in a intuitionistic fuzzy and random environment. Expert Systems with Applications, 40(16), 6459-6468.

Mattos, F., Garcia, P. (2011). Applications of behavioral finance to entrepreneurs and venture capitalists: decision making under risk and uncertainty in futures and options markets. In: Advances in Entrepreneurial Finance. Springer, New York, pp. 191-205.

Morente-Molinera, J.A., Kou, G., Pang, C., Cabrerizo, J., Herrera-Viedma, E. (2019). An automatic procedure to create fuzzy ontologies from users' opinions using sentiment analysis procedures and multi-granular fuzzy linguistic modelling methods. Information Sciences, 476, 222-238.

Nunes, J.C., Felix, E.G.S., Pires, C.P. (2014). Which criteria matter most in the evaluation of venture capital investments? Journal of Small Business and Enterprise Development, 21(3), 505-527.

Opricovic, S. (1998), Multi-Criteria Optimization of Civil Engineering Systes. Faculty of Civil Engineering, Belgrade.

Paelinck, J.H.P. (1978), Qualiflex: a flexible multiple-criteria method. Economics Letters, 1(3), 193-197.

Qin, Q.D., Liang, F.Q., Li, L., Chen, Y.W., Yu, G.F. (2017). A TODIM-based multi-criteria group decision making with triangular intuitionistic fuzzy numbers. Applied Soft Computing, 55, 93-107.

Ren, Z.L., Xu, Z.S., Wang, H. (2017). An extended TODIM method under probabilistic dual hesitant fuzzy information and its application on enterprise strategic assessment. In: IEEE International Conference on Industrial Engineering and Engineering Management. IEEE, pp. 1464-1468.

Rezaei, A. (2015). Best-worst multi-criteria decision-making method. Omega, 53, 59-57.

Roy, B. (1968). Classement et choix en présence de points de vue multiples (la methode ELECTRE). Revue Francaise D Informatique de Recherche Operationnelle, 2(8), 57-75.

Sang, X.Z., Liu, X.W. (2016). An interval type-2 fuzzy sets-based TODIM method and its application to green supplier selection. Journal of the Operational Research Society, 67(5), 722-734.

Srinivasan, V., Shocker, A.D. (1973). Linear programming techniques for multidimensional analysis of preference. Psychometrika, 38(3), 337-342.

Tan, C.Q., Jiang, Z.Z., Chen, X.H. (2015). An extended TODIM method for hesitant fuzzy interactive multicriteria decision making based on generalized Choquet integral. Journal of Intelligent and Fuzzy Systems, 29(1), 293-305. 
Tversky, A., Kahneman, D. (1992). Advances in prospect theory: cumulative representation of uncertainty. Journal of Risk and Uncertainty, 5(4), 297-323.

Wang, S.W., Liu, J. (2017). Extension of the TODIM method to intuitionistic linguistic multiple attribute decision making. Symmetry, 9(6), 95.

Wang, J., Wang, J.Q., Zhang, H.Y. (2016). A likelihood-based TODIM approach based on multi-hesitant fuzzy linguistic information for evaluation in logistics outsourcing. Computers and Industrial Engineering, 99(C), 287-299.

Wei, C.P., Ren, Z.L., Rodríguez, R.M. (2015). A hesitant fuzzy linguistic TODIM method based on a score function. International Journal of Computational Intelligence Systems, 8(4), 701-712.

Widyanto, H.A., Dalimunthe, Z. (2015). Evaluation Criteria of Venture Capital Firms Investing on Indonesians' SME. Social Science Electronic Publishing, New York.

Wu, G., Gonzalez, R. (1999). Nonlinear decision weights in choice under uncertainty. Management Science, 45(45), 74-85.

Yu, W.Y., Zhang, Z., Zhong, Q.Y., Sun, L.L. (2017). Extended TODIM for multi-criteria group decision making based on unbalanced hesitant fuzzy linguistic term sets. Computers and Industrial Engineering, 114, 316328.

Yu, S.M., Wang, J., Wang, J.Q. (2018). An extended TODIM approach with intuitionistic linguistic numbers. International Transactions in Operational Research, 25(3), 781-805.

Zavadskas, E.K., Turskis, Z. (2010). A new additive ratio assessment (ARAS) method in multicriteria decisionmaking. Technological and Economic Development of Economy, 16(2), 159-172.

Zavadskas, E.K., Kaklauskas, A., Sarka, V. (1994). The new method of multi-criteria complex proportional assessment of projects. Technological and Economic Development of Economy, 3, 131-139.

Zhang, X.L. (2017). A closeness index-based TODIM method for hesitant qualitative group decision making. Informatica, 28(3), 565-581.

Zhang, X.L., Xu, Z.S. (2014). The TODIM analysis approach based on novel measured functions under hesitant fuzzy environment. Knowledge-Based Systems, 61(2), 48-58.

Zhang, Y.X., Xu, Z.S. (2016). Efficiency evaluation of sustainable water management using the HF-TODIM method. International Transactions in Operational Research. doi:10.1111/itor.12318.

Zhang, W.K., Du, J., Tian, X.L. (2018). Finding a promising venture capital project with TODIM under probabilistic hesitant fuzzy circumstance. Technological and Economic Development of Economy, 24(5), 20262044.

Zhang, L., Zhan, J.M., Xu, Z.S. (2019). Covering-based generalized IF rough sets with applications to multiattribute decision-making. Information Sciences, 478, 275-302.

Zindani, D., Maity, S.R., Bhowmik, S., Chakraborty, S. (2017). A material selection approach using the TODIM (TOmada de Decisao Interativa Multicriterio) method and its analysis. International Journal of Materials Research, 108(5), 345-354. 
X. Tian is carrying out the PhD degree in Business School, Sichuan University. She received her master's degree in School of Economics, Sichuan University, China, in 2012. Currently, she has contributed articles to professional journals including Applied Soft Computing, Knowledge-Based Systems, Technological and Economic Development of Economy, etc. Her research interests include decision making with bounded rationality, uncertain multi-criteria decision making, consensus model, etc.

Z. Xu received the PhD degree in management science and engineering from Southeast University, Nanjing, China, in 2003. From April 2003 to May 2005, he was a postdoctoral researcher at the School of Economics and Management, Southeast University. From October 2005 to December 2007, he was a postdoctoral researcher at the School of Economics and Management, Tsinghua University, Beijing, China. He is a Distinguished Young Scholar of the National Natural Science Foundation of China and the Chang Jiang Scholars of the Ministry of Education of China. He is currently a professor at the Business School, Sichuan University, Chengdu. He has been elected to the grade of Fellow of IEEE (Institute of Electrical and Electronics Engineers) and IFSA (International Fuzzy Systems Association), selected as the Thomson Reuters Highly Cited Researcher (in the fields of Computer Science and Engineering, respectively). His h-index is 109, and he has authored twelve books published by Springer. He has contributed more than 680 journal articles to professional journals. His current research interests include information fusion, group decision making, computing with words, and aggregation operators. Dr. Xu is the associate editor of IEEE Transactions on Fuzzy Systems, Information Sciences, Fuzzy Optimization and Decision Making, International Journal of Fuzzy Systems, International Journal Machine Leaning and Cybernetics, etc. He is also a member of the editorial (advisory) boards of Knowledge-Based Systems, Information Fusion, Applied Intelligence, Technological and Economic Development of Economy, etc.

J. Gu received the $\mathrm{PhD}$ degree in school of management and economics from University of Electronic Science and Technology of China, Chengdu, China, in 2009. She is currently an associate professor of Economics School in Sichuan University. She has published over 30 journal articles and authored two monographs. She was also awarded as Distinguished Youth of Sichuan Province and Elite Youth Faculties of Sichuan University. Her research interest focuses on decision making and risk analysis. 